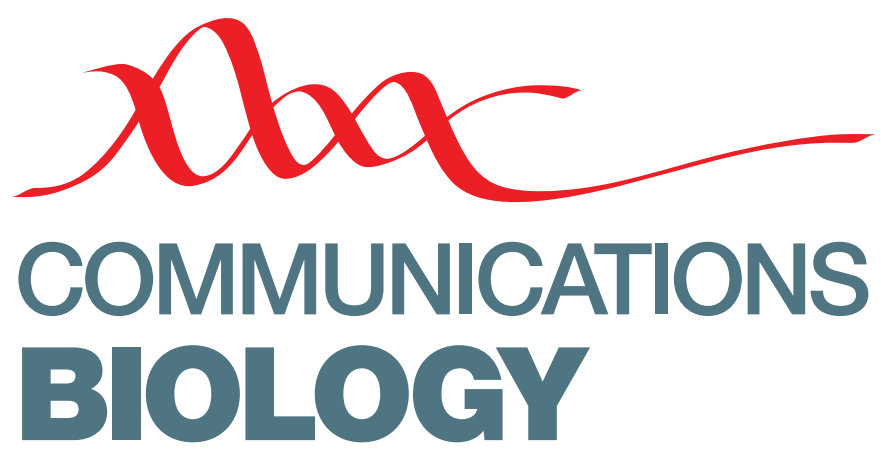

\title{
Publisher Correction: Estimating and explaining the spread of COVID-19 at the county level in the USA
}

Anthony R. Ives (1) \& Claudio Bozzuto (1)

Correction to: Communications Biology https://doi.org/10.1038/s42003-020-01609-6, published online 5 January 2021.

In the original version of the published manuscript, there was an error in Eq. 2 in which the tau was misplaced and denoted as a multiplier of the distribution of the proportion of secondary infections caused by a primary infection that occurred $\tau$ days previously (1) rather than as a power to which $\mathrm{r}(\mathrm{t})$ is raised (2)

(1) Original version $R(t)=1 / \sum_{\tau} \mathrm{e}^{-r(t)} \tau p(\tau)$

(2) Corrected version $R(t)=1 / \sum_{\tau} \mathrm{e}^{-r(t) \tau} p(\tau)$

Published online: 20 January 2021

\footnotetext{
(c) Open Access This article is licensed under a Creative Commons Attribution 4.0 International License, which permits use, sharing, adaptation, distribution and reproduction in any medium or format, as long as you give appropriate credit to the original author(s) and the source, provide a link to the Creative Commons license, and indicate if changes were made. The images or other third party material in this article are included in the article's Creative Commons license, unless indicated otherwise in a credit line to the material. If material is not included in the article's Creative Commons license and your intended use is not permitted by statutory regulation or exceeds the permitted use, you will need to obtain permission directly from the copyright holder. To view a copy of this license, visit http://creativecommons.org/licenses/by/4.0/.
}

(๑) The Author(s) 2021 